\title{
EL CASO CASTAÑEDA ANTE LA CORTE INTERAMERICANA DE DERECHOS HUMANOS
}

\author{
Carlos María PELAYo MÖLLER* \\ Santiago J. VÁZQUEZ CAMACHO**
}

\begin{abstract}
SUMARIO: I. Introducción. II. Procedimiento a nivel nacional $y$ en el sistema interamericano de promoción y protección a los derechos humanos. III. La decisión de la Corte Interamericana de Derechos Humanos en el caso Castañeda. IV. Reflexiones finales en torno a la sentencia de la Corte Interamericana de Derechos Humanos en el caso Castañeda.
\end{abstract}

\section{INTRODUCCIÓN}

El caso Castañeda es sin lugar a dudas uno de los casos que más polémica ha desatado en diversos medios de comunicación en México, no sólo porque versa sobre la pertinencia de regular las candidaturas independientes dentro del contexto político, jurídico y social mexicano, sino también porque el mismo involucró a diversas instancias nacionales e internacionales. ${ }^{1}$

El caso Castañeda es relevante, en primer lugar, porque es el primer caso resuelto por la Corte Interamericana de Derechos Humanos (en adelante Corte IDH) donde se condena a México por una violación a la Convención Americana sobre Derechos Humanos (en adelante la Convención). ${ }^{2}$ En segundo lugar, porque en instancias nacionales e internacionales

* LL. M. en derecho internacional de los derechos humanos por el Centro de Derechos Civiles y Humanos de la Universidad de Notre Dame.

** Licenciado en derecho por el Instituto Tecnológico Autónomo de México.

1 Véase Córdoba Vianello, Lorenzo, "Candidaturas independientes", Nexos, México, núm. 354, junio de 2007.

2 Por sentencia del 3 de septiembre de 2004, la Corte IDH resolvió el caso Alfonso Martín del Campo Dodd vs. Estados Unidos Mexicanos. En dicho caso la Corte IDH no se pronunció sobre el fondo del asunto, ya que declaró procedente la excepción preliminar de falta de competencia ratione temporis interpuesta por el Estado. 
el caso implicó discutir dos temas importantes: 1) el acceso de los ciudadanos a la justicia cuando alegan que una ley electoral, en este caso federal, viola sus derechos políticos consagrados en la Constitución Política de los Estados Unidos Mexicanos (en adelante la Constitución) y en la Convención, y 2) la compatibilidad con la Constitución y con la Convención del derecho exclusivo de los partidos políticos para registrar candidaturas a elección popular.

A continuación se describirán los hechos más importantes del caso Castañeda, se destacarán diversas cuestiones alrededor de los dos temas principales discutidos en la sentencia y, finalmente, se reflexionará sobre algunas cuestiones abiertas a modo de conclusión. ${ }^{3}$

\section{PROCEDIMIENTO A NIVEL NACIONAL Y EN EL SISTEMA INTERAMERICANO DE PROMOCIÓN Y PROTECCIÓN A LOS DERECHOS HUMANOS}

El 5 de marzo de 2004 el señor Jorge Castañeda Gutman presentó ante el Instituto Federal Electoral (IFE) su solicitud de registro como candidato independiente a la Presidencia de los Estados Unidos Mexicanos para las elecciones de 2006. El 12 de marzo de 2004 la Dirección Ejecutiva en Prerrogativas y Partidos Políticos del IFE notificó al señor Castañeda la negativa de su registro como candidato independiente, ya que conforme a la ley electoral: 1) corresponde exclusivamente a los partidos políticos nacionales el derecho de solicitar el registro de candidatos a cargos de elección popular, ${ }^{4}$ y 2) el plazo para el registro de candidaturas para presidente de los Estados Unidos Mexicanos abarca del 1o. al 15 de enero del año de la elección (es decir, enero de 2006). ${ }^{5}$

Ante la negativa del IFE, el señor Castañeda promovió el 29 de marzo de 2004 un amparo contra leyes, al considerar que dicha "negativa"

3 La información pública contenida en este artículo se puede consultar en las páginas de Internet de la Comisión Interamericana de Derechos Humanos (www.Corte IDH.org), y de la Corte Interamericana de Derechos Humanos (www.corteidh.or.cr).

4 Artículo 175. 1. Corresponde exclusivamente a los partidos políticos nacionales el derecho de solicitar el registro de candidatos a cargos de elección popular.

5 Artículo 177, párrafo 1, inciso e del abrogado COFIPE. 
era un acto de aplicación ${ }^{6}$ del artículo 175 del Código Federal de Procedimientos Electorales (Cofipe), ${ }^{7}$ que injustificadamente otorgaba el derecho de solicitar el registro de candidatos a cargos de elección popular de forma exclusiva a los partidos políticos. Para Castañeda tanto la ley como su acto de aplicación violaban - inter alia - su derecho político a ser votado, protegido por el artículo 35, fracción II, de la Constitución. ${ }^{8}$

Mediante sentencia del 16 de julio de 2004, el Juzgado Séptimo de Distrito en Materia Administrativa del Distrito Federal (en adelante el Juzgado de Distrito) declaró improcedente dicha demanda amparo con fundamento en los artículos 73, fracción VII, de la Ley de Amparo, ${ }^{9}$ y 105, fracción II, de la Constitución. ${ }^{10}$ Castañeda interpuso un recurso de revisión en contra de dicha sentencia, el cual fue atraído y resuelto por la Suprema Corte de Justicia de la Nación (en adelante la SCJN) con fechas

6 Conforme al ordenamiento jurídico mexicano, se puede considerar que la negati$v a$ de registro del IFE no debió ser considerada como un acto de aplicación de la ley en perjuicio del señor Castañeda por las autoridades mexicanas, en virtud de dos razones relacionadas con la falta de interés jurídico: i) el IFE emitió la "negativa" de registro en respuesta a una solicitud presentada fuera del plazo previsto en la ley (el señor Castañeda solicitó su registro antes del plazo que corría del 1o. al 15 de enero de 2006), por lo que en realidad la respuesta del IFE nunca tuvo efectos vinculatorios ni afectó la esfera jurídica del señor Castañeda (incluso el señor Castañeda podría haber solicitado su registro posteriormente durante el plazo previsto en la ley), y ii) la Dirección Ejecutiva de Prerrogativas y Partidos Políticos del IFE que dio respuesta a su solicitud no era la autoridad competente para admitir o rechazar los registros de las candidaturas, como posteriormente lo determinó el Tribunal Electoral del Poder Judicial de la Federación (en adelante el “TRIFE") en el 2006 en el caso del señor Héctor Montoya Fernández (véase la resolución del 2 de febrero de 2006 al juicio para la protección de los derechos político-electorales del ciudadano SUP-JDC-67/2006, que puede ser consultada en el sitio web del TRIFE: www.trife.org. $m x$ ).

7 El 14 de enero de 2008 fue publicado en el Diario Oficial de la Federación (DOF) el nuevo Cofipe. El artículo 175 del abrogado Cofipe fue sustituido por el artículo 218 que quedó redactado en los mismos términos.

8 Artículo 35. Son prerrogativas del ciudadano... II. Poder ser votado para todos los cargos de elección popular, y nombrado para cualquier otro empleo o comisión, teniendo las calidades que establezca la ley.

9 Artículo 73. El juicio de amparo es improcedente... VII. Contra las resoluciones o declaraciones de los organismos y autoridades en materia electoral.

10 Artículo 105. La Suprema Corte de Justicia de la Nación conocerá, en los términos que señale la ley reglamentaria, de los asuntos siguientes... II. De las acciones de inconstitucionalidad que tengan por objeto plantear la posible contradicción entre una norma de carácter general y esta Constitución... La única vía para plantear la no conformidad de las leyes electorales a la Constitución es la prevista en este artículo. 
8 y 16 de agosto de 2005 en el mismo sentido que el Juzgado de Distrito, es decir, sobreseyendo el juicio de garantías respecto de los artículos $175,176,177$, párrafo I, inciso e, y 178 del Cofipe, y respecto al acto concreto de aplicación contenido en el oficio del IFE. ${ }^{11}$

La SCJN consideró que la demanda de amparo del señor Castañeda era improcedente esencialmente porque:

la facultad de resolver sobre la contradicción de normas electorales a la Constitución federal, está plenamente limitada por mandato constitucional al Pleno de la Suprema Corte de Justicia de la Nación, mientras que el Tribunal Electoral conocerá respecto de algún acto o resolución o sobre la interpretación de un precepto constitucional, siempre que esta interpretación no sea para verificar la conformidad de una ley electoral con la Constitución. ${ }^{12}$

\section{Asimismo, sostuvo que:}

Aún cuando esta Suprema Corte de Justicia de la Nación ha sustentado excepcionalmente cuando junto con la violación de un derecho político se reclaman leyes o actos que entrañen la violación de garantías individuales, resulta procedente la demanda de amparo; sin embargo, en el caso no se está en ese supuesto de excepción.

Debido a que, como ya se ha señalado a lo largo de la presente resolución, en el presente caso lo que se pretende combatir a través del juicio de amparo es la violación de derechos políticos, que, aun cuando constituyan un derecho fundamental, inciden totalmente en cuestiones electorales, esto es, en la posibilidad de ser votado para un cargo de elección popular, como candidato independiente...

En ese sentido, y al estar en presencia de un asunto en el que lo sustancial a resolver es sobre el ejercicio del derecho político-electoral de ser votado, es clara la improcedencia del juicio de amparo, ya que la vía idónea es la acción de inconstitucionalidad o bien, los medios de control constitucional de que conoce el Tribunal Electoral. ${ }^{13}$

11 Sentencia del 8 y 16 de agosto de 2005 al amparo en revisión número 743/2005, que se puede consultar en la página electrónica de la Suprema Corte de Justicia de la Nación www.scjn.gob.mx, pp. 219 y 220.

12 Ibidem, p. 156.

13 Ibidem, pp. 206 y 209. 
El 12 de octubre de 2005, el señor Jorge Castañeda Gutman denunció ante la Comisión Interamericana de Derechos Humanos (en adelante la Comisión) la violación - inter alia - a sus derechos humanos consagrados en los artículos 23 (derechos políticos) ${ }^{14}$ y 25 (protección judicial) ${ }^{15}$ de la Convención. Asimismo, el señor Castañeda solicitó a la Comisión que adoptara medidas cautelares en su favor. ${ }^{16}$

El 17 de octubre de 2005 la Comisión dictó medidas cautelares que pedían a México que concediera al señor Castañeda el registro de su candidatura para presidente de los Estados Unidos Mexicanos mientras decidía acerca de la admisibilidad y el fondo de la cuestión. ${ }^{17}$ El 27 de octubre de 2005 México manifestó que su legislación interna impedía registrar la candidatura independiente del señor Castañeda. ${ }^{18}$

El 15 de noviembre de 2005, previo a que el caso fuera sometido a la Corte IDH, la Comisión solicitó a esta última que ordenara la adopción de medidas provisionales en el presente caso con el fin de que México adoptara las acciones necesarias para la inscripción de la candidatura del señor Jorge Castañeda Gutman a la Presidencia de la República mientras

14 Artículo 23. Derechos políticos. 1. Toda persona tiene derecho a un recurso sencillo y rápido o a cualquier otro recurso efectivo ante los jueces o tribunales competentes, que la ampare contra actos que violen sus derechos fundamentales reconocidos por la Constitución, la ley o la presente Convención, aun cuando tal violación sea cometida por personas que actúen en ejercicio de sus funciones oficiales. 2. Los Estados Partes se comprometen: a) a garantizar que la autoridad competente prevista por el sistema legal del Estado decidirá sobre los derechos de toda persona que interponga tal recurso; b) a desarrollar las posibilidades de recurso judicial, y c) a garantizar el cumplimiento, por las autoridades competentes, de toda decisión en que se haya estimado procedente el recurso.

15 Artículo 25. Protección Judicial. 1. Todos los ciudadanos deben gozar de los siguientes derechos y oportunidades: a) de participar en la dirección de los asuntos públicos, directamente o por medio de representantes libremente elegidos; b) de votar y ser elegidos en elecciones periódicas auténticas, realizadas por sufragio universal e igual y por voto secreto que garantice la libre expresión de la voluntad de los electores, y c) de tener acceso, en condiciones generales de igualdad, a las funciones públicas de su país. 2. La ley puede reglamentar el ejercicio de los derechos y oportunidades a que se refiere el inciso anterior, exclusivamente por razones de edad, nacionalidad, residencia, idioma, instrucción, capacidad civil o mental, o condena, por juez competente, en proceso penal.

16 Corte IDH, caso Castañeda Gutman. Medidas Provisionales, Resolución de la Corte del 25 de noviembre de 2005, visto 3 .

17 Idem.

18 Demanda de la Comisión Interamericana de Derechos Humanos en el caso de Jorge Castañeda Gutman (Caso 12.535) contra los Estados Unidos Mexicanos del 21 de marzo de 2007, párrafo 13. 
la Comisión decidía acerca de la admisibilidad y el fondo de la petición presentada, lo cual fue desestimado por la Corte IDH mediante resolución del 25 de noviembre de 2005 al considerar que la adopción de medidas provisionales implicaría un juzgamiento anticipado del objeto del debate principal de la demanda. ${ }^{19}$

Cabe destacar que el 6 de octubre de 2005 inició formalmente el periodo electoral, y del 1o. al 15 de enero de 2006 el IFE recibió las candidaturas para el cargo a la Presidencia de los Estados Unidos Mexicanos para las elecciones de 2006. El señor Castañeda no presentó solicitud de registro de su candidatura durante dicho plazo legal, conforme al artículo 177 del abrogado Cofipe. ${ }^{20}$

El 21 de diciembre de 2006 la Comisión notificó a México y al señor Castañeda su Informe de Admisibilidad y Fondo 113/06 del 26 de octubre de 2006, en el cual dicho organismo internacional sostuvo que

al impedir a Jorge Castañeda Gutman la presentación de su candidatura independiente a la Presidencia de México, el Estado ha incurrido en responsabilidad internacional por la violación del derecho a la protección judicial (artículo 25), conjuntamente con las obligaciones de respeto y garantía y el deber de adoptar disposiciones de derecho interno establecidos en la Convención Americana (artículos 1(1) y 2 , respectivamente). ${ }^{21}$

Tras considerar la respuesta de México sobre la implementación de las recomendaciones de la Comisión, dicho órgano decidió someter el caso a la Corte IDH. ${ }^{22}$

El 21 de marzo de 2007 la Corte IDH recibió la demanda de la Comisión en relación con el caso 12.535 del señor Castañeda, la cual sólo alegó la violación por parte de México al artículo 25 (protección judicial) en relación con los artículos 1o. y 2o. de la Convención. No obstante, los representantes del señor Castañeda alegaron en su escrito del 7 de junio

19 Corte IDH, op. cit., nota 16, considerandos 6 y 9.

20 Artículo 177. 1. Los plazos y órganos competentes para el registro de las candidaturas en el año de la elección son los siguientes... e) Para presidente de los Estados Unidos Mexicanos, del 1o. al 15 de enero inclusive, por el Consejo General.

21 Demanda de la Comisión Interamericana de Derechos Humanos en el caso de Jorge Castañeda Gutman (Caso 12.535) contra los Estados Unidos Mexicanos del 21 de marzo de 2007, párrafo 24.

22 Corte IDH, caso Castañeda Gutman vs. México, Excepciones Preliminares, Fondo, Reparaciones y Costas, sentencia del 6 de agosto de 2008, Serie C, núm. 184, párrafo 3. 
de 2007 adicionalmente la violación a los artículos 23 (derechos políticos) y 24 (igualdad ante la ley) en relación con los artículos 1.1 y 2o. de dicho tratado internacional, por lo que la Corte consideró analizar los argumentos relacionados con la violación de dichos preceptos, ya que así lo ha establecido dicho tribunal en casos anteriores mientras dichas violaciones tengan sustento en los mismos hechos presentados por la Comisión. ${ }^{23}$

La Corte IDH celebró una audiencia pública el 8 de febrero de 2008, en la que el señor Castañeda rindió su declaración testimonial y las partes manifestaron sus alegatos orales finales. El 6 de agosto de 2008 la Corte IDH emitió la sentencia que resolvió el caso Castañeda, pronunciándose sobre la alegada violación al artículo 25 de la Convención. La resolución de la Corte IDH condenó a México a completar, en un plazo razonable,

La adecuación de su derecho interno a la Convención, de tal forma que ajuste la legislación secundaria y las normas que reglamentan el juicio de protección de los derechos del ciudadano de acuerdo con lo previsto en la reforma constitucional de 13 de noviembre de 2007, de manera que mediante dicho recurso se garantice a los ciudadanos de forma efectiva el cuestionamiento de la constitucionalidad de la regulación legal del derecho a ser elegido. ${ }^{24}$

La Corte IDH condenó a México por violar el derecho del señor Castañeda a la protección judicial de sus derechos fundamentales, considerando esencialmente lo siguiente:

Dado que el recurso de amparo no resulta procedente en materia electoral, la naturaleza extraordinaria de la acción de inconstitucionalidad y la inaccesibilidad e inefectividad del juicio de protección para impugnar la falta

23 En lo que se refiere a la incorporación de otros derechos distintos a los ya comprendidos en la demanda presentada por la Comisión, la Corte ha considerado que "los peticionarios pueden invocar... derechos [distintos a los de la demanda de la Comisión. Toda vez que] son ellos los titulares de todos los derechos consagrados en la Convención Americana, y no admitirlo sería una restricción indebida a su condición de sujetos del Derecho Internacional de los Derechos Humanos". Véase Corte IDH, caso Cinco Pensionistas vs. Perú. Fondo, Reparaciones y Costas, sentencia del 28 de febrero de 2003, Serie C, núm. 98, párrafo 155 .

24 Corte IDH, op. cit., párrafo 231. 
de conformidad de una ley con la Constitución, en la época de los hechos del presente caso no había en México recurso efectivo alguno que posibilitara a las personas cuestionar la regulación legal del derecho político a ser elegido previsto en la Constitución Política y en la Convención Americana. En razón de ello, la Corte concluye que el Estado no ofreció a la presunta víctima un recurso idóneo para reclamar la alegada violación de su derecho político a ser elegido, y por lo tanto violó el artículo 25 de la Convención Americana, en relación con el artículo 1.1 del mismo instrumento, en perjuicio del señor Castañeda Gutman. ${ }^{25}$

Respecto al artículo 23 de la Convención, la Corte IDH siguió su test tradicional para determinar los límites de las restricciones a los derechos consagrados en la Convención, concluyendo que:

No considera probado en el presente caso que el sistema de registro de candidaturas a cargo de partidos políticos constituya una restricción ilegítima para regular el derecho a ser elegido previsto en el artículo 23.1.b de la Convención Americana y, por lo tanto, no ha constatado una violación al artículo 23 de dicho tratado. ${ }^{26}$

\section{LA DECISIÓN DE LA CORTE INTERAMERICANA DE DERECHOS HUMANOS EN EL CASO CASTAÑEDA}

A continuación se expondrán las razones principales de los jueces de la Corte IDH para concluir que México violó el derecho a la protección judicial de los derechos fundamentales del señor Castañeda conforme al artículo 25 de la Convención, pero no así su derecho político a ser votado para un cargo de elección popular conforme al artículo 23 de la Convención. ${ }^{27}$

25 Ibidem, párrafo 131.

26 Ibidem, párrafo 205.

27 El Estado mexicano interpuso un total de cuatro excepciones preliminares principales ante la Corte IDH en torno a la aplicación efectiva de la ley como requisito para la competencia de la Corte, la ausencia de la presunta víctima en el proceso electoral iniciado en octubre de 2005, la actuación de la Comisión en la tramitación del caso, y finalmente, la falta de agotamiento del recurso interno idóneo y la indebida interposición de un recurso inadecuado. La Corte IDH, antes de pronunciarse sobre el fondo de la controversia, desestimó las tres primeras excepciones preliminares y decidió analizar los argumentos de las partes respecto al agotamiento de los recursos internos en el fondo de la 


\section{La inexistencia en México de un recurso judicial accesible}

y efectivo para la protección de los derechos políticos del ciudadano cuando éstos son afectados por la aplicación de una ley que es considerada inconstitucional

La sentencia del 6 de agosto de 2008 de la Corte IDH dividió el estudio de la alegada violación del Estado mexicano al artículo 25 de la Convención en dos apartados: uno correspondiente al análisis del juicio de amparo y otro correspondiente al análisis del juicio para la protección de los derechos político-electorales de los ciudadanos. Este último apartado, a su vez, se subdividió en dos secciones: "accesibilidad del recurso" y "efectividad del recurso".

En relación con el amparo, la Corte IDH consideró, como lo reconocieron la Comisión y el Estado mexicano, "que el recurso de amparo interpuesto por la presunta víctima no era la vía adecuada en ese caso, dada su improcedencia en materia electoral", ${ }^{28}$ precisando que la limitación de las materias que se deben conocer a través del juicio de amparo es compatible con la Convención, siempre y cuando se prevea un recurso judicial de similar naturaleza para garantizar las materias excluidas. ${ }^{29}$ Así, la Corte IDH sostuvo que un recurso judicial para proteger los derechos humanos es efectivo mientras potencialmente permita al juez pronunciarse sobre el fondo, y el mismo garantice el debido proceso, sin que sea incompatible con la Convención el que se actualicen causales de improcedencia o admisibilidad que impidan al tribunal pronunciarse sobre el fondo del asunto. ${ }^{30}$

En relación con el juicio para la protección de los derechos político-electorales de los ciudadanos, la Corte IDH analizó dos cuestiones para determinar si México violó el derecho de protección judicial del señor Castañeda contenido en la Convención: i) la legitimación activa de los ciudadanos para acceder a dicho juicio, y ii) la competencia del Tribunal Federal Electoral (Trife) para poder declarar en casos concretos la inaplicabilidad de una ley que considere el ciudadano violatoria de sus derechos políticos fundamentales.

misma al determinar la existencia o no de una violación al artículo 25 de la Convención. Véase ibidem, párrafos 15-67.

28 Ibidem, párrafo 91.

29 Ibidem, párrafo 92.

30 Ibidem, párrafo 94. 
Respecto a la primera cuestión, la Corte IDH interpretó la normativa en ese tema, y concluyó que el juicio para la protección de los derechos político-electorales de los ciudadanos previsto en la Ley General del Sistema de Medios Impugnación en Materia Electoral (Ley de Impugnación Electoral) no podía ser considerado como un recurso judicial accesible en términos de la Convención, ya que los artículos 79 y 80 de la citada ley ${ }^{31}$ imponen una condición de procedencia injustificada en el supuesto de que un ciudadano considere violado su derecho político a ser votado y alegue una negativa injustificada de su registro como candidato a un cargo de elección popular: la propuesta de su candidatura por un partido político. ${ }^{32}$ Para llegar a dicha conclusión la Corte IDH, analizó jurisprudencia del Trife que fue aportada por el Estado mexicano. ${ }^{33}$

En este punto, cabe destacar que la Corte IDH estudió, como prueba presentada por el Estado, una sentencia dictada por el Trife con motivo del juicio para la protección de los derechos político-electorales de los ciudadanos interpuesto por el señor Hank Rhon. ${ }^{34}$ Uno de los argumentos del Estado mexicano para alegar la inexistencia de una violación por la falta de un recurso efectivo era probar que los ciudadanos tenían legitimación activa en el juicio para la protección de los derechos político-electorales de los ciudadanos. Al respecto, el Estado mexicano alegó que en un caso similar al del señor Castañeda - el caso del señor Hank Rhon-, el Trife había analizado el fondo de su reclamo consistente en

31 Artículo 79. 1. El juicio para la protección de los derechos político-electorales, sólo procederá cuando el ciudadano por sí mismo y en forma individual, haga valer presuntas violaciones a sus derechos de votar y ser votado en las elecciones populares, de asociarse individual y libremente para tomar parte en forma pacífica en los asuntos públi$\cos$ y de afiliarse libre e individualmente a los partidos políticos. En el supuesto previsto en el inciso e) del párrafo 1 del siguiente artículo, la demanda deberá presentarse por conducto de quien ostente la representación legítima de la organización o agrupación política agraviada.../ Artículo 80. 1. El juicio podrá ser promovido por el ciudadano cuando... d) Considere que se violó su derecho político-electoral de ser votado cuando, habiendo sido propuesto por un partido político, le sea negado indebidamente su registro como candidato a un cargo de elección popular. En los procesos electorales federales, si también el partido político interpuso recurso de revisión o apelación, según corresponda, por la negativa del mismo registro, el Consejo del Instituto o la Sala Regional, a solicitud de la Sala Superior, remitirán el expediente para que sea resuelto por ésta, junto con el juicio promovido por el ciudadano.

32 Corte IDH, op. cit., nota 22, párrafo 114.

33 Ibidem, párrafo 110.

34 Ibidem, párrafo 113. 
su registro como candidato a gobernador sin que hubiera sido propuesto por un partido político para un cargo de elección popular en la entidad federativa de Baja California. Al valorar la sentencia del Trife dictada en el caso del señor Hank Rhon, la Corte IDH consideró que dicho candidato sí había sido propuesto por un partido político (la coalición partidista "Alianza para que Vivamos Mejor"), cumpliéndose la condición que imponía la ley electoral para tener legitimación activa en el juicio, por lo que no podía considerase probado ante dicho tribunal internacional que el juicio para la protección de los derechos político-electorales fuera accesible en caso de que algún ciudadano, como el señor Castañeda, alegara una negativa injustificada de registro a un cargo de elección popular. ${ }^{35}$

Respecto a la segunda cuestión, la competencia del Trife para poder declarar en casos concretos la inaplicabilidad de una ley que considere el ciudadano violatoria de sus derechos políticos constitucionales, la Corte IDH consideró que el juicio para la protección de los derechos político-electorales de los ciudadanos no era un recurso judicial efectivo para proteger los derechos fundamentales del señor Castañeda en términos de la Convención, ya que la regulación electoral constitucional y legal y la jurisprudencia obligatoria de la SCJN impedían al Trife desaplicar una ley que fuera contraria a la Constitución en un caso concreto. ${ }^{36}$

En este punto, la Corte IDH interpretó el artículo 105, fracción II de la Constitución y el artículo 10 de la Ley de Impugnación Electoral, ${ }^{37}$ con la jurisprudencia obligatoria de la SCJN, en el sentido de que dicha normativa reservaba al Pleno de la SCJN la competencia para analizar la constitucionalidad de leyes en materia electoral a través de la regulación de un recurso judicial de carácter extraordinario como la acción de inconstitucionalidad, de manera que los ciudadanos no tenían garantizado un recurso judicial efectivo que les posibilitara cuestionar la constitucionalidad de una ley que regulara indebidamente sus derechos políticos. ${ }^{38}$

35 Sentencia SUP-JDC-695/2007 del Tribunal Electoral del Poder Judicial de la Federación que se puede consultar en la página electrónica www.trife.gob.mx.

36 Corte IDH, op. cit., nota 22, párrafos 118-131.

37 Artículo 10. 1. Los medios de impugnación previstos en esta ley serán improcedentes en los siguientes casos: a) Cuando se pretenda impugnar la no conformidad a la Constitución de leyes federales y locales.

38 Para la Corte IDH, el carácter extraordinario de la acción de inconstitucionalidad para impugnar una ley se deriva de que: i) la legitimación activa está limitada a ciertos órganos y fracciones parlamentarias; ii) la declaración de invalidez de las normas genera- 
Asimismo, es interesante cómo la Corte IDH se pronunció al analizar la efectividad del juicio para la protección de los derechos político-electorales de los ciudadanos sobre uno de los argumentos del Estado mexicano consistente en que dicho juicio era un recurso judicial efectivo en términos de la Convención, en virtud de que el Trife realizaba una forma interna de "control convencional" de leyes que garantizaba los derechos políticos, sin tener la necesidad de desaplicar una ley que el ciudadano considerara inconstitucional. Al respecto, la Corte IDH concluyó que México no probó que dicho "control convencional" interno se pudiera realizar respecto de leyes electorales de carácter federal, a diferencia de los casos del señor Hank Rhon, Manuel Guillén Monzón, María Mercedes Maciel y Eligio Valencia Roque presentados como prueba por el Estado mexicano, en los que aparentemente se hizo un "control convencional" interno de leyes de carácter local. ${ }^{39}$

De esta forma, la Corte IDH concluyó que el Estado mexicano debió prever en su legislación un recurso judicial efectivo e idóneo para que el señor Castañeda pudiera reclamar la alegada violación de su derecho político a ser elegido como candidato independiente. Así, la inexistencia de este recurso constituyó por si misma una violación a su derecho a la protección judicial (artículo 25) en relación con la obligación del Estado de respetar los derechos (artículo 1.1 de la Convención). ${ }^{40}$

Igualmente, la Corte determinó que dicha situación constituía un incumplimiento por parte de Estado de su deber de adoptar disposiciones de derecho interno para hacer efectivos los derechos establecidos en la Convención, debido a que el Estado mexicano no realizó las modificaciones necesarias para asegurar la ejecución de las obligaciones internacionales asumidas en virtud de la Convención, lo que constituyó una violación en perjuicio de señor Castañeda a su derecho a la protección judicial (artículo 25) en relación con la obligación de respetar los derechos (artículo 1.1) y con el deber de adoptar disposiciones de derecho interno (artículo 2o.) según lo dispone la Convención. ${ }^{41}$

les a través del mismo requiere el voto de cuando menos ocho ministros del Pleno de la SCJN, y iii) la misma sólo puede interponerse dentro de los 30 días naturales siguientes a la fecha de publicación de la ley de que se trate. Véase Corte IDH, op. cit., nota 22, párrafo 128.

39 Ibidem, párrafo 129.

40 Ibidem, párrafo 131.

41 Ibidem, párrafo 132 y 133. 


\section{La exclusividad de los partidos políticos para solicitar el registro de candidatos a elección popular}

Una vez declarada la violación al artículo 25 de la Convención, la Corte IDH analizó si México violó a través de su legislación federal el derecho a ser votado del señor Castañeda consagrado en el artículo 23 de la Convención, en relación con los artículos 1.1 y 2o. de la Convención. Para ello, la Corte siguió los siguientes pasos:

Primero, la Corte IDH determinó el contenido general de los derechos políticos en el artículo 23.1 de la Convención, concluyendo principalmente que los derechos políticos son derechos humanos de suma importancia en una sociedad democrática, al ser fines en sí mismos, y medios para garantizar otros derechos humanos, que incluso no pueden ser suspendidos conforme al artículo 27 de la Convención. ${ }^{42}$

Segundo, la Corte IDH interpretó el término "exclusivamente" en el artículo 23 párrafo 2 de la Convención, concluyendo que éste debe interpretarse conjuntamente con el párrafo 1 , y que el mismo se refiere a los titulares de los derechos políticos que son los ciudadanos, y a las posibles razones por las que un Estado "exclusivamente" podría restringir a esos titulares el goce de los derechos políticos siempre que dichas restricciones no fueran injustificadas (por ejemplo, conforme a la Convención, es válido hacer restricciones por la condición de edad pero no por la condición de raza del titular), sin que el término "exclusivamente" en dicho artículo implicara una prohibición de regulación al Estado (o de establecimiento de modalidades) de la organización de su sistema electoral. En todo caso, la Corte IDH sostuvo que para que la regulación electoral sea compatible con la Convención la misma no debe ser discriminatoria. ${ }^{43}$

Tercero, la Corte IDH concluyó que conforme a la Observación General núm. 25 del Comité de Derechos Humanos de la Organización de las Naciones Unidas (que analiza el contenido del artículo 25 del Pacto Internacional de Derechos Civiles y Políticos, cuyo texto es casi idéntico al artículo 23 de la Convención), los Estados pueden regular en su legislación la postulación de candidaturas exclusivamente a través de partidos políticos, mientras la misma sea razonable. La Corte IDH concluyó que dicha observación lo que prohíbe es que la regulación obligue, de forma

43 Ibidem, párrafo 158 y 166. 
excesiva, a que los candidatos sean miembros o afiliados de partidos políticos. ${ }^{44}$ Aquí cabe mencionar que en México no es requisito ser afiliado del partido político para ser postulado por el mismo a un cargo de elección popular.

Cuarto, la Corte IDH concluyó que el caso Yatama, un caso resuelto previamente en materia electoral por dicho tribunal, no era aplicable analógicamente al caso del señor Castañeda, ya que ambos casos no compartían las mismas propiedades relevantes, toda vez que mientras el requisito consistente en participar políticamente a través de un partido político para personas pertenecientes a una comunidad indígena es desproporcionado al traducirse en una forma ajena a sus usos, costumbres y formas de organización, dicho requisito no podría considerarse injustificado en el caso del señor Castañeda, en virtud de que no acreditó representar a una comunidad vulnerable o marginada, además de que tenía diversas alternativas para postularse como candidato a la presidencia conforme al sistema electoral mexicano: formar un partido político, ingresar a un partido político y por la vía interna ser nominado como candidato, ser postulado como candidato externo de un partido político o formar una agrupación política nacional. ${ }^{45}$

Quinto, la Corte IDH empleó su test tradicional ${ }^{46}$ para determinar si la norma que prevé el derecho exclusivo de los partidos políticos para registrar candidaturas a elección popular restringía injustificadamente el derecho político a ser votado del señor Castañeda consagrado en el artículo 23.1.b de la Convención. La metodología implicó analizar si la norma: i) está prevista en una ley formal y material; ii) persigue una finalidad legítima, y iii) es necesaria en una sociedad democrática. En este último punto se analizó si la medida responde a una necesidad social imperiosa, si la medida, igualmente idónea que otras, restringe en menor es-

44 Ibidem, párrafos 163 y 164.

45 Ibidem, párrafos 172 y 202.

46 Por test tradicional entendemos la metodología que ha sido utilizado por la Corte IDH en diversos casos para evaluar las condiciones que deben cumplir las restricciones que los Estados hacen a los derechos humanos contenidos en la Convención. Véase Medina Quiroga, Cecilia, La Convención Americana: teoría y jurisprudencia. Vida, integridad personal, libertad personal, debido proceso y recurso judicial, Universidad de Chile-Centro de Derechos Humanos, 2005, pp. 40-45. 
cala el derecho humano protegido y, si la medida se ajusta al logro de ese objetivo legítimo. ${ }^{47}$

Conforme al test tradicional para concluir si una norma es una restricción válida del derecho político a ser votado, la Corte IDH concluyó esencialmente lo siguiente para declarar que el Estado no violó el artículo 23 de la Convención:

i) La norma que otorga exclusivamente a los partidos políticos el derecho de registro de candidatos a elección popular (principalmente el artículo 175 del Cofipe) es una ley formal y material que interviene el derecho político a ser votado.

ii) La finalidad de organizar el proceso electoral y el acceso al ejercicio del poder público de los ciudadanos, en condiciones de igualdad y de manera eficaz perseguida por la norma legislativa, es legítima conforme a la Convención.

iii) El registro de candidatos a elección popular exclusivamente a través de partidos políticos responde a necesidades sociales imperiosas basadas en diversas razones históricas, políticas (la necesidad de crear y fortalecer el sistema de partidos) y sociales de México (la necesidad de organizar de manera eficaz el proceso electoral en una sociedad de 75 millones de electores, en las que todos tendrían el mismo derecho a ser elegidos; la necesidad de un sistema de financiamiento predominantemente público, para asegurar el desarrollo de elecciones auténticas y libres, en igualdad de condiciones, y la necesidad de fiscalizar eficientemente los fondos utilizados en las elecciones), sin que por otro lado el señor Castañeda hubiera brindado razones que desvirtuaran los fundamentos del Estado o justificaran una necesidad social imperiosa de regular las candidaturas independientes.

iv) Respecto al derecho político de ser votado, el sistema no regulado de registro de candidaturas a elección popular de forma independiente y a través de partidos políticos no puede considerase - en abstractouna medida igualmente idónea y menos restrictiva que el sistema de registro de candidatos a elección popular exclusivamente a través de partidos políticos, siendo esencial que los dos sistemas hagan accesible y garanticen el derecho y la oportunidad a ser votado de las personas en condiciones de igualdad. 
v) La exclusividad de registro de candidatos a elección popular a través de partidos políticos es una regulación idónea para alcanzar su finalidad legítima.

Finalmente, la Corte IDH no declaró una violación al artículo 24 de la Convención (igualdad ante la ley), argumentando que "las elecciones locales y las federales no son comparables, de modo que no es posible concluir que las diferencias de organización entre unas y otras, sean discriminatorias y violen el derecho a la igualdad ante la ley". ${ }^{48}$

\section{REFLEXIONES FINALES EN TORNO A LA SENTENCIA DE LA CORTE INTERAMERICANA DE DERECHOS HUMANOS EN EL CASO CASTAÑEDA}

\section{Sobre las candidaturas independientes en México}

Respecto a la alegada violación del artículo 23 de la Convención, hay que tener en cuenta que el 8 de julio de 2008, un mes antes de la sesión de la Corte IDH del 6 de agosto, la SCJN resolvió la acción de inconstitucionalidad 61/2008 y sus acumuladas, declarando la validez constitucional del artículo 218 del nuevo Cofipe, publicado el 14 de enero de 2008. ${ }^{49}$ Dicho artículo sustituyó con el mismo contenido normativo al artículo 175 del Cofipe vigente en el caso Castañeda, otorgando a los partidos políticos el derecho exclusivo de registrar a candidatos de elección popular, al igual que el precepto anterior..$^{50}$

En este sentido, podría concluirse que la misma SCJN dentro del Estado mexicano - aunque por diferentes razones que habrán de analizarse al momento en que dicho tribunal publique el "engrose" de la sentencia-, está de acuerdo con que dicha norma no viola los derechos políticos de los ciudadanos desde la perspectiva del control abstracto constitucional.

La norma que concede a los partidos políticos el derecho exclusivo para solicitar el registro de candidatos a cargos de elección popular (el

48 Ibidem, párrafo 212.

49 Véase la versión taquigráfica de la sesión pública ordinaria del Pleno de la Suprema Corte de Justicia de la Nación del 3 de julio de 2008, que puede ser consultada en la página electrónica de dicho tribunal www.scjn.gob.mx.

50 Artículo 218. 1. Corresponde exclusivamente a los partidos políticos nacionales el derecho de solicitar el registro de candidatos a cargos de elección popular. 
artículo 175 del Cofipe) en sí misma no viola el derecho político al voto, ya que ésta - per se- no excluye ni discrimina a las personas en el ejercicio de su derecho a ser votado: cualquier ciudadano que desee ser candidato a un cargo de elección popular puede hacerlo a través de los partidos políticos, incluso, sin la necesidad de estar afiliado a los mismos.

Como indicó la Corte IDH, en su sentencia, los sistemas electorales que incluyen las candidaturas independientes así como los sistemas electorales construidos sobre la base exclusiva de partidos políticos son compatibles con la Convención:

La Corte considera que ambos sistemas, uno construido sobre la base exclusivamente de partidos políticos, y otro que admite también candidaturas independientes, pueden ser compatibles con la Convención y, por lo tanto, la decisión de cuál sistema escoger está en las manos de la definición política que haga el Estado, de acuerdo con sus normas constitucionales. A la Corte le queda claro que en la región existe una profunda crisis en relación con los partidos políticos, los poderes legislativos y con quienes dirigen los asuntos públicos, por lo que resulta imperioso un profundo y reflexivo debate sobre la participación y la representación política, la transparencia y el acercamiento de las instituciones a las personas, en definitiva, sobre el fortalecimiento y la profundización de la democracia. La sociedad civil y el Estado tienen la responsabilidad, fundamental e inexcusable de llevar a cabo esta reflexión y realizar propuestas para revertir esta situación. En este sentido, los Estados deben valorar de acuerdo con su desarrollo histórico y político las medidas que permitan fortalecer los derechos políticos y la democracia, y las candidaturas independientes pueden ser uno de esos mecanismos, entre muchos otros. ${ }^{51}$

Es importante destacar que la Corte IDH afirmó que el derecho internacional no impone un sistema electoral determinado ni una modalidad específica de ejercer los derechos a votar y a ser elegido, al interpretar las normas que regulan los derechos políticos tanto en el ámbito universal como en el regional, y analizar las interpretaciones autorizadas realizadas por sus órganos de aplicación. ${ }^{52}$ En específico, la Corte IDH señaló

51 Corte IDH, op. cit., nota 22, párrafo 204.

52 Ibidem, párrafo 162. Al respecto, la Corte IDH citó la Observación general núm. 25 , Derecho a participar en los asuntos públicos, derecho a votar y derecho al acceso, en condiciones de igualdad a las funciones públicas (artículo 25) del 12 de julio de 1996 del 
que el sistema interamericano tampoco impone un sistema electoral determinado ni una modalidad específica para el ejercicio de los derechos a votar y a ser elegido, toda vez que la Convención Americana establece lineamientos generales que determinan un contenido mínimo de los derechos políticos y permite a los Estados que dentro de los parámetros convencionales regulen esos derechos de acuerdo a sus necesidades históricas, políticas, sociales y culturales, las que pueden variar de una sociedad a otra, e incluso en una misma sociedad, en distintos momentos históricos. ${ }^{53}$

En este sentido, la resolución de la Corte IDH fue una decisión afortunada tomando en cuenta que un tribunal internacional en materia de derechos humanos no podría por sí mismo decidir racionalmente qué sistema electoral es el más apropiado para un determinado Estado. Es así que conforme a la Convención, cada Estado democráticamente, a través de sus representantes parlamentarios y autoridades, debe ser libre de regular su sistema electoral conforme a su realidad social, política, histórica y cultural, siempre y cuando dicho sistema garantice los derechos humanos de las personas en condiciones de igualdad y no discriminación, así como los principios esenciales del sistema democrático representativo que dan coherencia también a las normas del sistema interamericano de protección y promoción de los derechos humanos.

Sin embargo, esto no implica que en el seno del Poder Legislativo de los diferentes Estados que forman parte de la Convención o en diversos foros de opinión popular, no se deba discutir si en un momento dado sería conveniente regular las candidaturas independientes, como en su momento lo han hecho países como Chile, Colombia, Ecuador, Honduras, República Dominicana o Venezuela, de forma complementaria a los partidos políticos. ${ }^{54}$

Finalmente, consideramos que la crisis de los partidos políticos en muchos países de América no se resolvería con una "llave mágica" denominada candidaturas independientes. No se trata de tapar el sol con un dedo. Dentro de la agenda política sería más importante mejorar - for-

Comité de Derechos Humanos de las Naciones Unidas, y los casos Mathieu-Mohin and Clerfayt vs. Bélgica y Zdanoka vs. Letonia del Tribunal Europeo de Derechos Humanos.

53 Ibidem, párrafo 166.

54 Véase Peza de la, José Luis, "Candidaturas independientes", en Nohlen, Dieter et al., Tratado de derecho electoral comparado de América latina, 2a. ed., México, FCE, 2007, pp. 620-623. 
mal y materialmente - las instituciones electorales en el país antes que regular las candidaturas independientes: 1) la regulación para transparentar los procedimientos internos de los partidos políticos y el destino de los recursos públicos a los que tienen derecho; 2) la eliminación de costos innecesarios de las instituciones parlamentarias y del gasto absurdo de los partidos políticos; 3) la fiscalización de la procedencia de los recursos privados de los partidos políticos; 4) la regulación de los espacios de comunicación social, sobre todo en periodos electorales; 5) la obligación de los partidos políticos de incluir en la toma de decisiones a grupos vulnerables o excluidos socialmente; 6) la mejora de la imagen pública que se tiene en los países latinoamericanos de "lo político", y de toda organización política o fracción parlamentaria; 7) el fomento en los ciudadanos de la participación activa en la cuestiones públicas, sea individualmente o de forma organizada; 8) la mejora de la preparación académica de los representantes populares y de la calidad del debate público, o 9) la eliminación de factores de "personalización" o de "mercantilización" de la política y su consecuente sustitución por factores que fomenten la creación de plataformas políticas y consensos sólidos dentro de los partidos y organizaciones de carácter político.

\section{Sobre el acceso a la justicia en materia electoral en México}

Respecto a la violación del artículo 25 de la Convención, es relevante que la sentencia de la Corte IDH reafirme la distinción práctica entre el derecho humano de acceso a la justicia y el derecho humano que se alega violado ante un tribunal (en este caso el derecho humano a ser votado en elecciones públicas): es posible que un Estado viole el primero sin que necesariamente se declare la violación del segundo conforme a la Convención, y sin que esto implique una contradicción.

Sin duda, todas las personas tienen derecho a que, una vez que cumplan supuestos de procedencia razonables previstos legalmente para acceder a recursos judiciales que protejan sus derechos humanos, los tribunales escuchen sus argumentos y decidan racionalmente si el Estado violó o no sus derechos humanos. La regulación del sistema judicial de un Estado no debe excluir de dicha posibilidad de argumentación a los ciudadanos que aleguen que sus derechos humanos han sido conculcados, y ello incluye a los derechos humanos de carácter político. 
Por otro lado, desde una perspectiva de los derechos humanos, no hay duda de que en México los derechos políticos han sido tratados constitucionalmente (tal vez por herencia del antes "partido hegemónico") como derechos humanos de "segunda categoría": no son justiciables a través del recurso de amparo, el cual ha sido el único recurso previsto tradicionalmente para que las personas se "amparen" contra leyes violatorias de sus derechos fundamentales; apenas en 1996 empezaron las reformas que otorgaron la competencia al Trife para resolver casos en que los ciudadanos alegaran la inconstitucionalidad o ilegalidad de actos - no leyes - de las autoridades electorales que vulneraran sus derechos políticos, y, recientemente, en noviembre de 2007 se reformó el artículo 99 de la Constitución con la finalidad de que, por primera vez, los ciudadanos pudieran a través de los medios de impugnación electoral desaplicar una ley federal o local en materia electoral que fuera contraria a la Constitución en un caso concreto, lo cual no era posible conforme a la reforma constitucional electoral de 1996 y la jurisprudencia obligatoria de la SCJN de 2002.55

Si bien México dio un paso adelante con la reciente reforma constitucional que faculta al Trife para revisar la constitucionalidad de leyes electorales en casos concretos, queda pendiente la supervisión que hará la Corte IDH del cumplimiento de las reparaciones que ordenó al Estado mexicano. En México sería necesario revisar si la reciente reforma publicada el 1o. de julio de 2008 a la Ley de Impugnación Electoral y a la Ley Orgánica del Poder Judicial de la Federación cumple cabalmente con los extremos de la sentencia de la Corte IDH en el caso Castañeda, de forma tal que, sin ambigüedades y vaguedades, los nuevos medios de impugnación en materia electoral que se regulen posibiliten a los ciudadanos, de forma accesible y efectiva, desaplicar leyes electorales que consideren contrarias a la Constitución o a la Convención por violar sus derechos

55 Artículo 99. El Tribunal Electoral será, con excepción de lo dispuesto en la fracción II del artículo 105 de esta Constitución, la máxima autoridad jurisdiccional en la materia y órgano especializado del Poder Judicial de la Federación... Sin perjuicio de lo dispuesto por el artículo 105 de esta Constitución, las salas del Tribunal Electoral podrán resolver la no aplicación de leyes sobre la materia electoral contrarias a la presente Constitución. Las resoluciones que se dicten en el ejercicio de esta facultad se limitarán al caso concreto sobre el que verse el juicio. En tales casos la Sala Superior informará a la Suprema Corte de Justicia de la Nación. 
humanos de carácter político, en especial el derecho a ser votado en elecciones públicas periódicas.

Cabe apuntar que la sentencia de la Corte IDH no legitima ni deslegitima el proceso electoral por el que se eligió a Felipe Calderón Hinojosa como actual presidente de la República mexicana, tampoco es el resultado de una revisión que avale toda la regulación constitucional y legal del sistema electoral mexicano, ni establece que toda reforma electoral deba hacerse a nivel de legislación secundaria sin reformarse la Constitución, como lo han sostenido algunas personas en diversos medios. ${ }^{56}$

La misión de la Corte IDH únicamente consistió en determinar si en el caso del señor Castañeda Gutman el Estado mexicano violó su derecho humano de acceso a la justicia y su derecho humano político a ser votado en cargos de elección popular. La Corte IDH concluyó que México solamente violó su derecho humano de acceso a la justicia, al impedirle la misma legislación electoral argumentar ante un tribunal competente la inconstitucionalidad de una ley electoral que presuntamente violaba su derecho humano político a ser votado para acceder a un cargo de elección popular. Como México reformó anticipadamente su Constitución, sólo le queda pendiente, entre otras reparaciones, adecuar su legislación secundaria para que los ciudadanos tengan un recurso contra leyes electorales que violen sus derechos humanos en casos concretos. ${ }^{57}$

56 Véase Carrasco Araizaga, Jorge, "Calderón, exigencia democrática”, Revista Proceso, 5 de septiembre de 2008, http://www.proceso.com.mx/opinion_articulo.php?articu $l o=61983$, y "Revés de la Corte Interamericana a Jorge Castañeda", 2 de septiembre de 2008, http://www2.esmas.com/noticierostelevisa/mexico/009908/reves-corte-interameri cana-jorge-castaneda.

57 La Corte IDH determinó en los puntos resolutivos de la Sentencia que: i) la misma constituye per se una forma de reparación, y ii) el Estado debe, en un plazo razonable, adecuar su legislación secundaria y las normas que reglamentan el juicio de protección de los derechos del ciudadano de acuerdo con lo previsto en la reforma constitucional de 13 de noviembre de 2007, de manera que mediante dicho recurso se garantice a los ciudadanos de forma efectiva el cuestionamiento de la constitucionalidad de la regulación legal del derecho a ser elegido. Además, la Corte IDH ordenó al Estado mexicano publicar en el Diario Oficial de la Federación y en otro diario de amplia circulación nacional, por una sola vez, los párrafos 77 a 133 de la Sentencia y la parte resolutiva de la misma, en el plazo de seis meses. La Corte también ordenó el pago al señor Jorge Castañeda Gutman de US\$ 7,000 (siete mil dólares de los Estados Unidos de América), por reintegro de costas y gastos, dentro del plazo de seis meses contado a partir de la notificación de la Sentencia. Por último, la Corte señaló que supervisará el cumplimiento íntegro de la sentencia. Véase Corte IDH. caso Castañeda Gutman vs. México. Excepciones Prelimi- 
Es así como la Corte IDH resolvió el caso Castañeda, el primero en el que se ha declarado como violado un derecho humano de un mexicano. Sin embargo, la agenda de México ante la Corte IDH todavía no ha terminado, ya que ante la misma se encuentran dos casos pendientes de resolución ante dicha instancia internacional que son de gran trascendencia para el país: uno es el caso Campo Algodonero de Claudia Ivette González, Esmeralda Herrera Monreal y Laura Berenice Ramos Martínez, que se refiere a la situación de asesinatos de mujeres en Ciudad Juárez, ${ }^{58}$ y el otro es el caso de Rosendo Radilla Pacheco referente al periodo histórico denominado en México como "la guerra sucia". ${ }^{9}$

nares, Fondo, Reparaciones y Costas, sentencia del 6 de agosto de 2008, Serie C, núm. 184, Puntos Resolutivos 5-9.

58 La demanda interpuesta en este caso por la Comisión Interamericana de Derechos Humanos puede ser consultada en el sitio web de la Comisión: http://www.Corte IDH. org/demandas/demandasESP2007.htm. Véase también Comisión Interamericana de Derechos Humanos, Comunicado de Prensa 59/07, "CIDH presenta demanda ante la Corte IDH", 10 de diciembre de 2007.

59 La demanda interpuesta en este caso por la Comisión Interamericana de Derechos Humanos puede ser consultada en el sitio web de la Comisión: http://www.Corte IDH. org/demandas/demandasESP2008.htm. Véase también Comisión Interamericana de Derechos Humanos, Comunicado de Prensa 13/08, "CIDH presenta demanda ante la Corte IDH", 1o. de abril de 2008. 